\title{
Birth Preparedness and Complication Readiness among Pregnant Women Attending Antenatal Classes at Primary Health Center in Ibadan, Nigeria
}

\author{
Margaret Akinwaare* ${ }^{*}$, Abimbola Oluwatosin \\ Department of Nursing, College of Medicine, University of Ibadan, Ibadan, Nigeria \\ Email: *margaretakinwaare@gmail.com
}

How to cite this paper: Akinwaare, M. and Oluwatosin, A. (2019) Birth Preparedness and Complication Readiness among Pregnant Women Attending Antenatal Classes at Primary Health Center in Ibadan, Nigeria. Open Journal of Obstetrics and Gynecology, 9, 1358-1364.

https://doi.org/10.4236/ojog.2019.910131

Received: August 26, 2019

Accepted: October 14, 2019

Published: October 17, 2019

Copyright $\odot 2019$ by author(s) and Scientific Research Publishing Inc. This work is licensed under the Creative Commons Attribution International License (CC BY 4.0).

http://creativecommons.org/licenses/by/4.0/

\section{(c) (i) Open Access}

\begin{abstract}
Maternal mortality has been reported to be a challenge globally, with the highest maternal mortality in Africa. However, the first target for the third Sustainable Development Goal (SDG) is to reduce the global maternal mortality ratio to less than 70 per 100,000 live births by 2030 . To achieve this goal, pregnant women's knowledge of birth preparedness and complication readiness (BPCR) is a key. Therefore, this study set out to assess knowledge of birth preparedness and complication readiness among pregnant women attending antenatal classes. This pilot study adopted a descriptive cross-sectional study design using quantitative approach. Structured questionnaire was used to generate data from 46 respondents after obtaining ethical approval for the study. All data collected were adequate for data analysis. The mean age is 27.71 years with a standard deviation of 5.85 , the average booking time was 4.69 months. Among the respondents who had given birth before, the average number of children was two children (1.8571). After categorizing the knowledge scores, $52.2 \%$ of the women have good knowledge of obstetric danger signs, $20(43.5 \%)$ of the women have poor knowledge of BPCR and 32 $(69.6 \%)$ of the respondents have good knowledge of skilled birth attendants. In conclusion, there is a need to formulate policies and strategies that will help to improve pregnant women's knowledge of BPCR if the first target of the third SDG will be achieved.
\end{abstract}

\section{Keywords}

Birth Preparedness, Complication Readiness, Skilled Birth Attendance, Pregnancy, Childbirth 


\section{Introduction}

The World Health Organization (WHO) has a vision of universal coverage of health care [1] which corroborates the third Sustainable Development Goal (SDG) - to ensure healthy lives and promote wellbeing for all at all ages [2]. However, due to disparity in the health systems, pregnant women in developing countries like Nigeria have a high risk of mortality [3]. The risk of maternal mortality in the sub-Saharan region is estimated to be 1 in 38 [4], while is estimated to be 1 in 3700 in the developed nations of the world. Additionally, the maternal mortality ratio (MMR) in Nigeria is at 814 per 100,000 live births, this contributes $62 \%$ of maternal deaths in the world [4]. In spite of this high MMR, there are proven interventions that are known to prevent maternal deaths. These include birth preparedness and complication readiness (BPCR) resulting in skilled attendance for pregnancy and childbirth as well as access to emergency obstetric care. It is obvious that women should be knowledgeable about birth preparedness and complication readiness [5]. The knowledge will empower them and their families to make prompt decisions to seek skilled care from health facilities during pregnancy, childbirth and immediately after delivery [6]. A previous study [7] conducted among pregnant women in Nigeria documented high awareness of the concept of BPCR, however, knowledge of obstetric danger signs which is a sub-set of BPCR was reported to be poor in the same study. Although, it is expected that pregnant women who receive antenatal care are supposed to be educated on BPCR, yet there is limited information on knowledge of BPCR among pregnant who received antenatal care. It is, therefore, important to have information on the knowledge of BPCR among pregnant women which is paramount to improved skilled birth attendance and subsequently to the reduction of maternal and neonatal mortality. We, therefore, assessed the knowledge of pregnant women on birth preparedness and complication readiness as well as their knowledge of skilled birth attendants.

\section{Methodology}

A pilot study which adopted a descriptive cross-sectional design and utilized quantitative approach was conducted among pregnant women attending antenatal clinic in a health facility in Iddo local government area of Ibadan, Nigeria. Random sampling technique was used to select a primary healthcare center and a total of 46 respondents (which is $10 \%$ of the calculated sample size for a planned intervention study in another setting) were purposively selected for the study using the inclusion criteria of pregnant women who have registered and were attending antenatal clinic in the selected health facility. The instrument for the study was a validated instrument (semi-structured/structured questionnaire) adapted from the "Monitoring birth preparedness and complication readiness tools and indicators for maternal and new-born health" developed by Johns Hopkins Program for International Education in Gynaecology and Obstetrics [5]. It was modified in consultation with experts in the field of reproductive as 
well as maternal and child health researcher, clinician (practitioner) and statistician. It contained 59 items which were sub-divided into sections A - F. Section A: socio-demographic characteristics; section B: past and present obstetric history; section C: knowledge of obstetric danger signs; section D: knowledge of birth preparedness and complication readiness; section E: attitude towards birth preparedness and complication readiness and section F: knowledge of skilled birth attendants. The knowledge score was classified as good knowledge at 50\% and above. The study has $100 \%$ response rate from data collection and all the data collected were adequate for data analysis. Ethical approval was obtained prior to the commencement of data collection. Preliminary checking of the questionnaires for error was done. The data was entered into SPSS version 21, double-entry was done to reduce error. Percentages were used to summarize categorical variables, while the mean and standard deviation was used to summarize continuous variables. Chi-square was used for hypothesis testing, the statistical significance of independent variables' effect was set at $\mathrm{p}<0.05$.

\section{Results and Comments}

Few $2(4.3 \%)$ of the participant are single while the rest of them are married, only $1(2.2 \%)$ of the women has no formal education. Also, 34 (73.9\%) of the participants are Muslims while there was none practicing traditional religion (Table 1).

The minimum age of the respondents is 18 years and the average age is 27.71 years with a standard deviation of 5.85 , some of the participants delay their booking as late as the 7 months, though the average booking time was 4.69 months. Among the participants who had given birth before, the average number of children was 2 children i.e. (1.8571) (Table 2).

After categorizing the classes of the scores; 24 (52.2\%) of the women has good knowledge of obstetric danger signs, 20 (43.5\%) of the women has poor knowledge of birth preparedness and complication readiness while $32(69.6 \%)$ of the participants have good knowledge of skilled birth attendants (Table 3).

Despite high awareness of birth preparedness and complication readiness reported among nursing mothers in a previous study [7] in Nigeria, yet a poor knowledge of birth preparedness and complication readiness was reported by another study [8] among pregnant women.

The hypotheses testing reveals that there is no significant association between the clients' educational level and knowledge at all levels (Table 4).

\section{Discussion}

The booking visit for pregnant women serves as their entry point for antenatal care. Hence, the World Health Organization (WHO) recommended booking to be done at/or before three months (12 weeks) of pregnancy in focused antenatal care model and to be done before four months (14 weeks) in traditional antenatal model [9]. However, this study revealed that some of the respondents delayed 
Table 1. Socio-demographic characteristics of the respondents.

\begin{tabular}{|c|c|c|}
\hline Variables & Frequency & Percent \\
\hline \multicolumn{3}{|l|}{ Marital Status } \\
\hline Single & 2 & 4.3 \\
\hline Married & 44 & 95.7 \\
\hline \multicolumn{3}{|l|}{ Highest educational level } \\
\hline No formal education & 1 & 2.2 \\
\hline Incomplete secondary school & 5 & 10.9 \\
\hline Complete secondary school & 24 & 52.2 \\
\hline Tertiary education & 16 & 34.8 \\
\hline \multicolumn{3}{|l|}{ Religion } \\
\hline Christianity & 12 & 26.1 \\
\hline Islam & 34 & 73.9 \\
\hline \multicolumn{3}{|l|}{ Ethnicity } \\
\hline Yoruba & 44 & 95.7 \\
\hline Others & 2 & 4.3 \\
\hline \multicolumn{3}{|l|}{ Husband's Highest educational level } \\
\hline Incomplete Secondary School & 1 & 2.3 \\
\hline Complete secondary school & 19 & 44.2 \\
\hline Tertiary education & 23 & 53.5 \\
\hline \multicolumn{3}{|l|}{ Is this your first pregnancy } \\
\hline No & 28 & 60.9 \\
\hline Yes & 18 & 39.1 \\
\hline \multicolumn{3}{|c|}{ How many delivery(ies) have you had } \\
\hline One & 11 & 39.3 \\
\hline Two & 12 & 42.9 \\
\hline Three & 3 & 10.7 \\
\hline \multicolumn{3}{|c|}{ Have you had any delivery in any other place apart from the hospital } \\
\hline No & 21 & 75.0 \\
\hline Yes & 7 & 25.0 \\
\hline
\end{tabular}

Table 2. Descriptive statistics.

\begin{tabular}{lcccccc}
\hline \multicolumn{1}{c}{ Variables } & $\mathrm{N}$ & Min. & Max & Mean & Std. Dev \\
\hline $\begin{array}{l}\text { Age of respondent } \\
\text { How many months pregnant are you now }\end{array}$ & 45 & 18.00 & 42.00 & 27.7111 & 5.8489 \\
$\begin{array}{l}\text { How many months pregnant were you when you came for } \\
\text { antenatal booking }\end{array}$ & 44 & 3.00 & 9.00 & 6.1818 & 1.5778 \\
$\begin{array}{l}\text { How many times have you attended antenatal clinic since } \\
\text { you got pregnant }\end{array}$ & 45 & 0.00 & 10.00 & 3.0667 & 2.3002 \\
$\begin{array}{l}\text { How many delivery(ies) have you had } \\
\text { Hon }\end{array}$ & 28 & 1.00 & 4.00 & 1.8571 & 0.8909
\end{tabular}


Table 3. Frequency of knowledge score class.

\begin{tabular}{ccc}
\hline Variable & Frequency & Percent \\
\hline Knowledge of obstetric danger signs & & \\
\hline Good & 24 & 52.2 \\
Poor & 22 & 47.8 \\
\hline Knowledge of birth preparedness and complication readiness & & \\
\hline Good & 26 & 56.5 \\
Poor & 20 & 43.5 \\
\hline Knowledge of skilled birth attendants & & \\
\hline Good & 32 & 69.6 \\
Poor & 14 & 30.4 \\
\hline
\end{tabular}

Table 4. Hypotheses testing.

\begin{tabular}{|c|c|c|c|c|c|}
\hline \multicolumn{6}{|c|}{ Knowledge of obstetric danger signs } \\
\hline Variables & Good Knowledge & Poor Knowledge & Total & $\mathrm{X}^{2}$ & P-value \\
\hline \multicolumn{6}{|l|}{ Educational Level } \\
\hline Primary school and below & $1(100.0)$ & $0(0.0)$ & 1 & 0.949 & 0.622 \\
\hline Secondary school & $15(51.7)$ & $14(48.3)$ & 29 & & \\
\hline Tertiary & $8(50.0)$ & $8(50.0)$ & 16 & & \\
\hline Total & $24(52.2)$ & $22(47.8)$ & 46 & & \\
\hline \multicolumn{6}{|c|}{ Knowledge of birth preparedness and complication readiness } \\
\hline \multicolumn{6}{|l|}{ Educational Level } \\
\hline Primary school and below & $0(0.0)$ & $1(100.0)$ & 1 & 1.352 & 0.509 \\
\hline Secondary school & $17(58.6)$ & $12(41.4)$ & 29 & & \\
\hline Tertiary & $9(56.3)$ & $7(43.8)$ & 16 & & \\
\hline Total & $26(56.5)$ & $20(43.5)$ & 46 & & \\
\hline \multicolumn{6}{|c|}{ Knowledge of skilled birth attendants } \\
\hline \multicolumn{6}{|l|}{ Educational Level } \\
\hline Primary school and below & $1(100.0)$ & $0(0.0)$ & 1 & 4.509 & 0.105 \\
\hline Secondary school & $17(58.6)$ & $12(41.4)$ & 29 & & \\
\hline Tertiary & $14(87.5)$ & $2(12.5)$ & 16 & & \\
\hline Total & $32(69.6)$ & $14(30.4)$ & 46 & & \\
\hline
\end{tabular}

their booking until seven months and the average booking time for all the respondents is five months. This is a big concern for midwives and other stakeholders in obstetrics. Delay in antenatal booking reduces the chances of exposing pregnant women to enough antenatal education, which could eventually be responsible for poor knowledge of BPCR [10] [11] [12]. Furthermore, this has also been corroborated by other studies in Africa [13] [14] which reported that not all pregnant women who attend antenatal clinic are educated on BPCR. This has been further proven by the findings of this study which showed that almost half 
of the respondents demonstrated poor knowledge of BPCR despite their antenatal clinic attendance.

In addition, another perspective of this poor knowledge of BPCR despite antenatal clinic attendance could be that BPCR education is not inclusive in the antenatal education offered to pregnant women. Hence, there is need to review content of antenatal education.

Moreover, the hypothesis testing revealed that the knowledge of BPCR is not influenced by the educational level or qualification of the respondents. This could be as a result of small sample size and could also be a limitation for this study. Further studies may look at having large number of respondents to increase the power of the study.

\section{Conclusion}

Maternal mortality remains a public health problem in developing countries including Nigeria. Adequate knowledge of birth preparedness and complication readiness by pregnant women, families, communities and healthcare workers will help in reducing the menace. Educating pregnant women on birth preparedness and complication readiness is a key.

\section{Conflicts of interest}

The authors declare no conflict of interest regarding the publication of this paper.

\section{References}

[1] World Health Organization (2019) National Health Policies, Strategies and Plans. https://www.who.int/

[2] United Nations (2015) The Millennium Development Goals Report. New York. https://www.un.org/

[3] WHO (2014) Universal Health Coverage. https://www.who.int/features/qa/universal_health_coverage/en/

[4] WHO, UNFPA, World Bank (2012) Trends in Maternal Mortality: 1990-2010. https://www.who.int/

[5] JHPIEGO (2004) Maternal and Neonatal Health. Monitoring Birth Preparedness and Complication Readiness, Tools and Indicators for Maternal and Newborn Health. Johns Hopkins, Bloomberg School of Public Health, Center for Communication Programs, Family Care International. http://pdf.dec.org/pdf_docs

[6] Pembe, A., Urassa, D., Carlstedt, A., Lindmark, G., Nystrom, L. and Darj, E. (2009) Rural Tanzanian Women's Awareness of Danger Signs of Obstetric Complications. BMC Pregnancy Childbirth, 9, Article No. 12.

https://doi.org/10.1186/1471-2393-9-12

[7] Ekabua, J.E., Ekabua, K.J., Odusolu, P., Agan, T.U., Iklaki, C.U. and Etokidem, A.J. (2011) Awareness of Birth Preparedness and Complication Readiness in South-Eastern Nigeria. ISRN Obstetrics and Gynecology, 2011, Article ID: 560641. https://doi.org/10.5402/2011/560641

[8] Emma-Ukaegbu, U.C., Nwokeukwu, H.I. and Uzochukwu, B.S.C. (2014) An As- 
sessment of Birth Preparedness and Complication Readiness in Antenatal Women in Umuahia North Local Government Area, Abia State, Nigeria. Journal of Dental and Medical Sciences, 13, 90-94. https://doi.org/10.9790/0853-131109094

[9] Aduloju, O.P., Akintayo, A.A., Ade-Ojo, I.P., Awoleke, J.O., Aduloju, T. and Ogundare, O.R. (2016) Gestational Age at Initiation of Antenatal Care in a Tertiary Hospital, Southwestern Nigeria. Nigerian Journal of Clinical Practice, 19, 772-777. https://doi.org/10.4103/1119-3077.181398

[10] Hiluf, M. and Fantahun, M. (2007) Birth Preparedness and Complication Readiness among Women in Adigrat Town, North Ethiopia. Ethiopian Journal of Health Development, 22, 14-20. https://doi.org/10.4314/ejhd.v22i1.10057

[11] Iliyasu, Z., Abubakar, I.S., Galadanci, H.S. and Aliyu, M.H. (2010) Birth Preparedness, Complication Readiness and Fathers' Participation in Maternity Care in a Northern Nigerian Community. African Journal Reproductive Health, 14, 21-32.

[12] Markos, D. and Bogale, D. (2014) Birth Preparedness and Complication Readiness among Women of Child Bearing Age Group in Gobaworeda, Oromia Region, Ethiopia. BMC Pregnancy Childbirth, 14, Article No. 282.

https://doi.org/10.1186/1471-2393-14-282

[13] Pembe, A., Carlstedt, A., Urassa, D., Lindmark, G., Nystrom, L. and Darj, E. (2010) Quality of Antenatal Care in Rural Tanzania: Counselling on Pregnancy Danger Signs. BMC Pregnancy Childbirth, 10, Article No. 35 https://doi.org/10.1186/1471-2393-10-35

[14] Magoma, M., Requejo, J., Merialdi, M., Campbell, O.M., Cousens, S. and Filippi, V. (2011) How Much Time Is Available for Antenatal Care Consultations? Assessment of the Quality of Care in Rural Tanzania. BMC Pregnancy Childbirth, 11, Article No. 64. https://doi.org/10.1186/1471-2393-11-64 